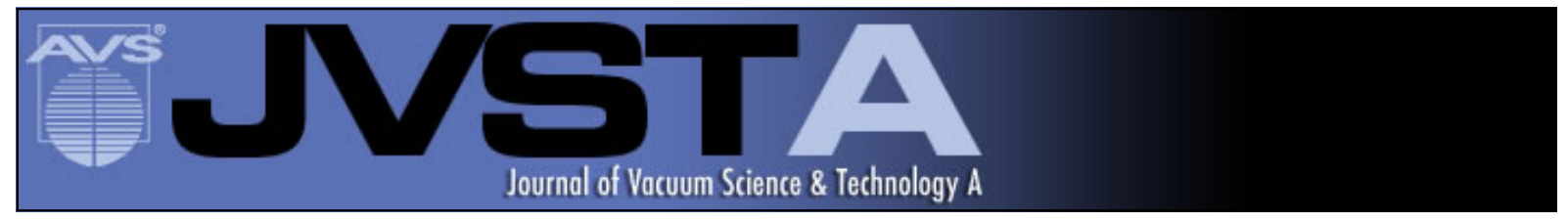

\title{
Structural and optical characteristics of tantalum oxide grown by pulsed Nd:YAG laser oxidation
}

E. Atanassova, G. Aygun, R. Turan, and Tz. Babeva

Citation: Journal of Vacuum Science \& Technology A 24, 206 (2006); doi: 10.1116/1.2165656

View online: http://dx.doi.org/10.1116/1.2165656

View Table of Contents: http://scitation.aip.org/content/avs/journal/jvsta/24/2?ver=pdfcov

Published by the AVS: Science \& Technology of Materials, Interfaces, and Processing

\section{Articles you may be interested in}

Infrared optical properties of amorphous and nanocrystalline Ta2O5 thin films

J. Appl. Phys. 114, 083515 (2013); 10.1063/1.4819325

Embedded argon as a tool for sampling local structure in thin plasma deposited aluminum oxide films

J. Appl. Phys. 112, 103306 (2012); 10.1063/1.4767383

Optical characteristics of pulsed laser deposited $\mathrm{Ba} 0.8 \mathrm{Sr} 0.2 \mathrm{TiO} 3$ thin films grown on fused quartz substrate AIP Conf. Proc. 1451, 139 (2012); 10.1063/1.4732393

Preparation of $\alpha$ - Al 2 O 3 thin films by electron cyclotron resonance plasma-assisted pulsed laser deposition and heat annealing

J. Vac. Sci. Technol. A 26, 380 (2008); 10.1116/1.2899569

Optical and structural properties of siliconlike films prepared by plasma-enhanced chemical-vapor deposition J. Appl. Phys. 97, 023533 (2005); 10.1063/1.1830092

\section{Instruments for Advanced Science} Contact Hiden Analytical for further details:
W www.HidenAnalytical.com
G info@hiden.co.uk CLICK TO VIEW our product catalogue

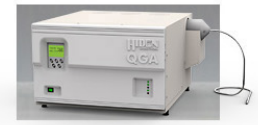

Gas Analysis

dynamic measurement of reaction gas streams catalysis and thermal analysis molecular beam studies

, fermentation, environmental and ecological studies

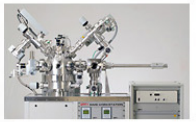

Surface Science

, UHVTPD

, SIMS

end point detection in ion beam etch elemental imaging - surface mapping

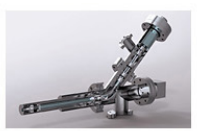

Plasma Diagnostics ' plasma source characterization etch and deposition process reaction , kinetic studies analysis of neutral and radical species

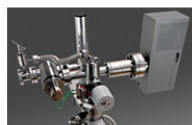

Vacuum Analysis ' partial pressure measurement and control of process gases reactive sputter process control vacuum diagnostics vacuum coating process monitoring 


\title{
Structural and optical characteristics of tantalum oxide grown by pulsed Nd:YAG laser oxidation
}

\author{
E. Atanassova \\ Institute of Solid State Physics, Bulgarian Academy of Sciences, Sofia 1784, Bulgaria \\ G. Aygun ${ }^{\text {a) }}$ \\ Department of Physics, Middle East Technical University, TR-06531 Ankara, Turkey \\ and Department of Physics, Izmir Institute of Technology, TR-35430 Urla, Izmir, Turkey \\ R. Turan \\ Department of Physics, Middle East Technical University, TR-06531 Ankara, Turkey \\ Tz. Babeva \\ Central Laboratory of Photoprocesses, Bulgarian Academy of Sciences, Sofia 1113, Bulgaria
}

(Received 2 June 2005; accepted 12 December 2005; published 8 February 2006)

\begin{abstract}
Tantalum pentoxide $\left(\mathrm{Ta}_{2} \mathrm{O}_{5}\right)$ thin films $(20-50 \mathrm{~nm})$ have been grown by $1064 \mathrm{~nm} \mathrm{Nd:YAG} \mathrm{laser}$ oxidation of Ta film deposited on $\mathrm{Si}$. The chemical bonding, structure, and optical properties of the films have been studied by Fourier transform infrared spectroscopy, x-ray diffraction, and reflectance measurements at normal light incidence in the spectral range of 350-800 $\mathrm{nm}$. The effect of the substrate temperature $\left(250-400{ }^{\circ} \mathrm{C}\right)$ during oxidation and its optimization with respect to the used laser beam energy density $\left(3.2-3.4 \mathrm{~J} / \mathrm{cm}^{2}\right.$ per pulse) is discussed. It is established that the substrate temperature is a critical factor for the effectiveness of the oxidation process and can be used to control the composition and amorphous status of the films. The film density explored by refractive index is improved with increasing film thickness. The refractive index of the layers grown under the higher laser beam energy density and at substrate temperature of $350-400{ }^{\circ} \mathrm{C}$ was found to be close to the value of bulk $\mathrm{Ta}_{2} \mathrm{O}_{5}$. The films are amorphous at substrate temperature below $350{ }^{\circ} \mathrm{C}$ and possessed an orthorhombic $\left(\beta-\mathrm{Ta}_{2} \mathrm{O}_{5}\right)$ crystal structure at higher temperatures. The thinner layers crystallize at a little higher temperature. (C) 2006 American Vacuum Society.
\end{abstract}

[DOI: $10.1116 / 1.2165656]$

\section{INTRODUCTION}

In order to overcome the scaling limit of conventional $\mathrm{SiO}_{2}$-based insulators due to high tunneling currents and reliability concerns, high permittivity (high- $\kappa$ ) materials, such as single metal oxides and their silicates as well as ferroelectrics, are being developed as alternative dielectrics in high-density metal-oxide-semiconductor field-effect transistors (MOSFETs) and dynamic random access memories (DRAMs). ${ }^{1}$ In that respect, $\mathrm{Ta}_{2} \mathrm{O}_{5}$ is considered as the promising candidate to replace $\mathrm{SiO}_{2}$ as a dielectric in storage capacitors of Gigascale DRAMs, (sub-100 nm technology node). ${ }^{1,2}$ It has gained the attention as a memory dielectric mainly due to its maturity in storage capacitors, namely, the excellent step coverage characteristics and high dielectric constant combined with relatively low leakage currents enabling high values of storage charge. After many years of development, the $\mathrm{Ta}_{2} \mathrm{O}_{5}$-based DRAMs are being produced by some manufacturers. ${ }^{2}$ In consequence, a number of compatible methods such as rf sputtering, thermal oxidation of Ta film, a variety of chemical-vapor deposition techniques, ionbeam deposition, atomic layer deposition, pulsed laser deposition have been developed to fabricate $\mathrm{Ta}_{2} \mathrm{O}_{5}$ films. ${ }^{2-19}$ Investigations on the production methodology continue in

a) Author to whom correspondence should be addressed; electronic mail: aygun@newton.physics.metu.edu.tr competition with alternative solution and each method exhibits advantages and disadvantages in terms of, mainly, electrical properties that are essential for DRAM applications. It is not yet clear which method will be chosen as the best one with respect to the storage capacitor applications because each fabricated method strongly affects the structural and electrical properties of the $\mathrm{Ta}_{2} \mathrm{O}_{5}$. The prospect of replacing $\mathrm{SiO}_{2}$ as a dielectric in DRAMs is a challenge considering that $\mathrm{SiO}_{2}$ is an excellent dielectric material from the manufacturing point of view. Among the various fabrication methods, the technique of pulsed laser oxidation (PLO) is of a special interest, in general for high- $\kappa$ dielectrics, mainly by two reasons: (i) it has potential for nanoscale application as a technique of local oxidation of small spots and (ii) since PLO operates at low substrate temperatures, it can minimize a number of problems which occur at high processing temperatures of most high- $\kappa$ dielectrics (and, in particular, of $\mathrm{Ta}_{2} \mathrm{O}_{5}$ ) such as undesirable reactions of the dielectrics with underlying Si resulting in a reduction of the benefits of high$\kappa$ material. If PLO meets the requirements for producing high-quality films with high dielectric constant, this would have considerable impact on the future high- $\kappa$ dielectric technology. It is, then, worthwhile to investigate the optimization of the parameters of PLO to obtain the best methodology for the future applications. At present, there is a limited amount of experimental data for the properties of laser- 
grown $\mathrm{Ta}_{2} \mathrm{O}_{5}$ from the storage capacitor DRAM application point of view. This article presents results for structural and optical properties of $\mathrm{Ta}_{2} \mathrm{O}_{5}$ formed by pulsed $\mathrm{Nd}$ :YAG (yttrium-aluminum-garnet) laser oxidation of Ta film on Si. Special attention is paid to the influence of the substrate temperature on the effectiveness of the oxidation process in terms of structural perfections, amorphous status of the films, and their refractive index values. The properties of lasergrown thin $\mathrm{Ta}_{2} \mathrm{O}_{5}$ films $(20-50 \mathrm{~nm})$ were characterized using Fourier transform infrared (FTIR) spectroscopy and reflectance measurements at normal light incidence. The presence of crystal phase(s) in the layers was determined by $\mathrm{x}$-ray diffraction (XRD) method.

\section{EXPERIMENTAL PROCEDURE}

The p-type (100) $15-17 \Omega \mathrm{cm} \mathrm{Si}$ wafers were used as substrates. After conventional chemical cleaning of the wafers, tantalum films with a thickness from 10 to about $20 \mathrm{~nm}$ were deposited on $\mathrm{Si}$ by $\mathrm{rf}$ sputtering of tantalum target (99.99\% purity) in an Ar atmosphere, (the system's base pressure was $6 \times 10^{-4} \mathrm{~Pa}$, the working gas pressure was $3 \mathrm{~Pa}$, rf power density was $2.2 \mathrm{~W} / \mathrm{cm}^{2}$, and the deposition rate was $9.3 \mathrm{~nm} / \mathrm{min}$; the substrate was not intentionally heated during the tantalum deposition and presumably remained at temperatures close to room temperature). Subsequently, the samples were laser oxidized in vacuum chamber which was evacuated to a base pressure below $0.13 \mathrm{~Pa}$. The substrate was heated to temperatures between 250 and $400{ }^{\circ} \mathrm{C}$ during the oxidation. $\mathrm{O}_{2}$ gas was introduced into the chamber (working gas pressure $p$ was $123 \mathrm{~Pa}$ ) after reaching the desired substrate temperature, $T_{s}$. The Nd:YAG laser with multiple shots corresponding to applied time durations at 1064 nm, (EKSPLA Pulsed Laser NL301) was used to induce the oxidation. The laser output is composed of a pulse train with individual pulses typically of $4.7 \mathrm{~ns}$. More details on the laser system and laser parameters can be found in Refs. 20 and 21, where we reported data of Nd:YAG laseroxidized thin $\mathrm{SiO}_{2}$ films showing parameters close to thermally grown $\mathrm{SiO}_{2}$. The approach used is only briefly described here. A computer-controlled $X-Y$ scanner system was used to direct the laser beam on a certain region on the substrate with controllable dimensions. By means of the scanner system, the laser beam was scanned over an area on the substrate of approximately $4 \times 4 \mathrm{~mm}^{2}$ and it can be further reduced or increased by the software. The speed of the scanner system is $0.3 \mathrm{~mm} / \mathrm{s}$. The main laser fluence varied in the range between 3.2 and $3.4 \mathrm{~J} / \mathrm{cm}^{2}$ per pulse. The oxide thickness, $d$, and the refractive index, $n$, of the oxide layers obtained were initially determined by single wavelength ellipsometry, $(\lambda=632.8 \mathrm{~nm})$; the films with $d=20-50 \mathrm{~nm}$ were studied. Additionally, both the refractive index and the film thickness were determined ${ }^{22}$ with high accuracy in the spectral range $\lambda=350-800 \mathrm{~nm}$, using reflectance measurements (Varian Cary 5E spectrophotometer with an accuracy of $0.5 \%$ ) at normal light incidence. $n$ and $d$ of the layer were obtained by minimization of the objective function using the substrate trust region method based on the interior-reflective
Newton method. ${ }^{23}$ More details on the calculating procedure used can be found elsewhere. ${ }^{21,22}$ The thickness, dispersion energy, and the single-oscillator energy were varied until a good fit between the measured and calculated values of reflectance was found (accuracy better than $0.5 \%$ ). The fit was accepted as successful when a good enough accordance (as good as $1 \mathrm{~nm}$ ) between ellipsometrically measured and obtained after this fitting thickness was achieved. The preliminary experiments showed that the laser oxidation of a tantalum film with a thickness of about $d / 2$ resulted in the formation of a tantalum-oxide film with a thickness about $d$. Laser exposure times in the range of about 30-60 min were used. However, we have observed that the properties of the oxide layer do not have a significant change between 30 and $60 \mathrm{~min}$ laser exposure times. Therefore, almost all time durations in the figures have $30 \mathrm{~min}$ laser oxidation times. A FTIR spectrometer (BRUKER Equinox 55) was used to obtain information on both the chemical composition and the structure of the films as a function of various oxidation parameters. The crystallinity of the films was examined by taking XRD patterns (Rigaku Miniflex system equipped with $\mathrm{Cu} K \alpha$ radiation of average wavelength $1.54059 \AA$ ). The patterns were analyzed by a computer software and ICDD database which includes the diffraction patterns of well-known structures. The peak matching process was carried out based on the observed peak positions at specific $2 \theta$ values and relative intensities of the peaks.

\section{RESULTS AND DISCUSSION}

\section{A. FTIR spectra}

The FTIR spectra produced from laser-oxidized layers with initial $10 \mathrm{~nm}$ Ta films on $\mathrm{Si}$ are discussed in this section. Samples with $20 \mathrm{~nm}$ Ta layer and their oxidation behavior at both different $T_{s}$ and laser beam energy density, $P$, are similar to those presented here. The spectra were taken between 400 and $4000 \mathrm{~cm}^{-1}$, but since the low wavenumber region $\left(<1100 \mathrm{~cm}^{-1}\right)$ is more important for detection of tantalum-oxide-related bonds, only the region of $400-1200 \mathrm{~cm}^{-1}$ is presented in the figures. OH peaks (around 3300-3400 $\mathrm{cm}^{-1}$ ) for all the samples without clear dependence on $T_{s}$ and $P$ are detected. This signal is, however, negligible, suggesting that the films are almost moisture poor. It is expected that postoxidation annealing will remove the little amount of moisture.

Figure 1(a) shows the evolution of FTIR spectra of oxide layers for which the laser beam energy density was kept constant at $3.2 \mathrm{~J} / \mathrm{cm}^{2}$ and $T_{s}$ was varied between 250 and $400{ }^{\circ} \mathrm{C}$. At the lowest substrate temperature, the effect of laser oxidation is very poor; only a small absorption line around $650 \mathrm{~cm}^{-1}$ associated with Ta-O-Ta and Ta-O stretching modes are seen in the spectrum. As $T_{s}$ increases to $300{ }^{\circ} \mathrm{C}$, a shoulderlike band appears in $480-560 \mathrm{~cm}^{-1}$ region and the absorption at $650 \mathrm{~cm}^{-1}$ becomes more pronounced. With further increasing of $T_{s}$, this line is formed as a dominant absorption feature between $\sim 650$ and $720 \mathrm{~cm}^{-1}$. These changes in the spectrum indicate the enhancement 


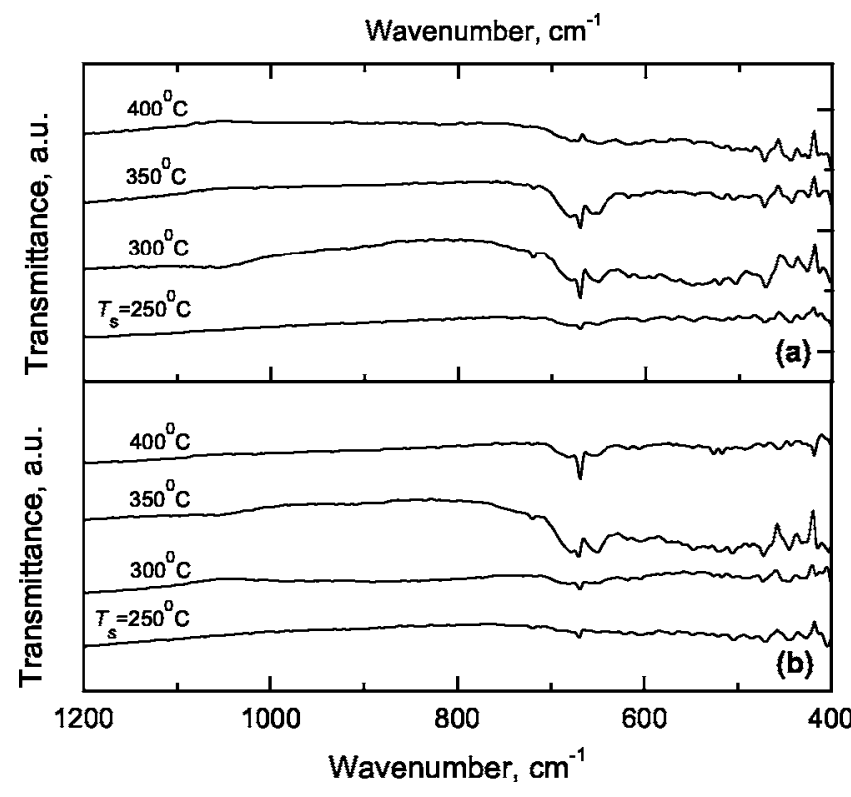

FIG. 1. FTIR spectra of the layers obtained at various substrate temperatures and laser beam energy densities of (a) $3.2 \mathrm{~J} / \mathrm{cm}^{2}$ and (b) $3.3 \mathrm{~J} / \mathrm{cm}^{2}$.

of the presence of the tantalum oxide(s) in the layers. ${ }^{15,24}$ The character of the shoulder does not apparently change at $T_{s}>300{ }^{\circ} \mathrm{C}$ and the spectra corresponding to $T_{s}$ of 350 and $400{ }^{\circ} \mathrm{C}$ are indistinguishable in this region. The feature at $670 \mathrm{~cm}^{-1}$ which is superimposed on the main broad signal is associated with vibration modes of $\mathrm{CO}_{2}$ resulting probably from the air ambient during the measurements. We will not discuss this peak further, since it is not related to the oxidation process itself. On the other hand, the absorption dip is unexpectedly smaller for the highest substrate temperature sample than those of the samples oxidized at lower $T_{s}$. This is believed to result from variations in the laser beam energy density and focusing system. This behavior is not seen in the next sample set presented below. The effect of $T_{s}$ upon the spectra of the films obtained at laser beam energy density of $3.3 \mathrm{~J} / \mathrm{cm}^{2}$ is shown in Fig. 1(b). The tendency of variation of the spectra is similar to that in Fig. 1(a), namely, the sample oxidized at the lowest substrate temperature exhibits only negligible absorption at around $650 \mathrm{~cm}^{-1}$; the intensity of this line increases a little and a wide shoulderlike absorption band appears between 450 and $550 \mathrm{~cm}^{-1}$, when $T_{s}=300{ }^{\circ} \mathrm{C}$. At $T_{s}=350$ and $400{ }^{\circ} \mathrm{C}$, this broad absorption band reduces whereas, the intensity of the peak at $650 \mathrm{~cm}^{-1}$ increases. These results suggest that the layers become denser with increasing $T_{s}$ and the effect is obviously stronger for a higher laser beam energy density. It emerges that the substrate temperature during laser oxidation is the critical factor determining the effectiveness of the process, and the effective laser oxidation of Ta at $T_{s}=250{ }^{\circ} \mathrm{C}$ is not possible. The impact of substrate temperature on the oxidation process implies that the oxygen diffusion can be invoked to explain the mechanism of oxidation. The laser oxidation process, however, goes under very complex conditions and it is not possible to make an explicit inference on the mechanism of oxidation based only on the present experimental data. More complex

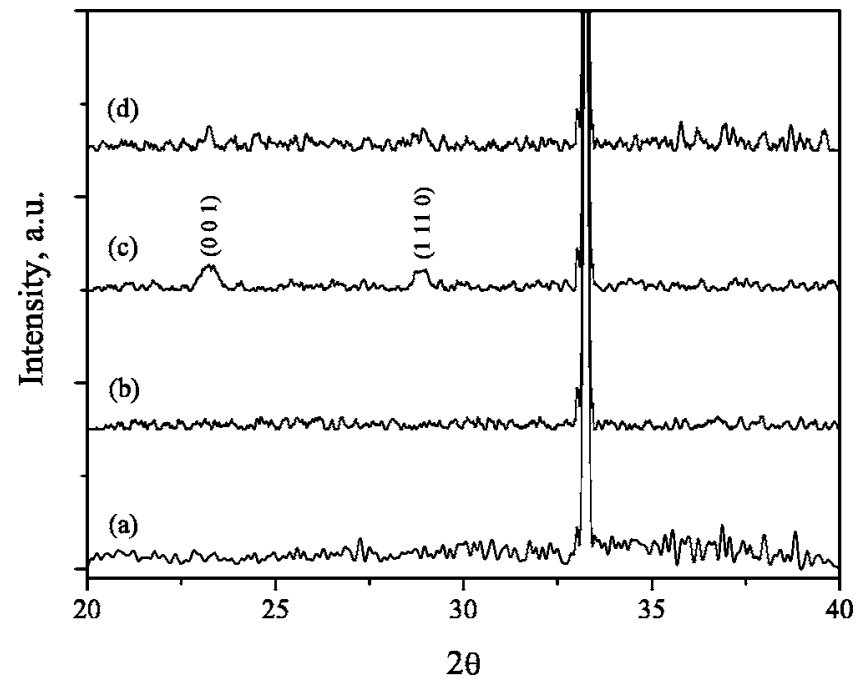

FIG. 2. XRD spectra of $\mathrm{Ta}_{2} \mathrm{O}_{5}$ layers $(22$ and $41 \mathrm{~nm})$ grown at various $T_{s}: d=22 \mathrm{~nm}, T_{s}=300{ }^{\circ} \mathrm{C}(\mathrm{a}) ; 350{ }^{\circ} \mathrm{C}(\mathrm{b}) ; 400{ }^{\circ} \mathrm{C}(\mathrm{c}) ; d=41 \mathrm{~nm}, T_{s}$ $=350{ }^{\circ} \mathrm{C}, 400{ }^{\circ} \mathrm{C}(\mathrm{d}) ;\left(P=3.3 \mathrm{~J} / \mathrm{cm}^{2}\right)$.

analysis (including the effect of partial pressure of oxygen) is necessary to clarify the mechanism of oxidation and to determine the dominant oxidizing component of the process and such an analysis is beyond the scope of this work.

Under the light of experimental evidences presented, we can conclude that the laser oxidation of $\mathrm{Ta}$ film on $\mathrm{Si}$ takes place without presence of significant amount of suboxides. Only for $T_{s}=300,350{ }^{\circ} \mathrm{C}, P=3.3 \mathrm{~J} / \mathrm{cm}^{2}$, [Fig. 1(b)] the shoulder, respectively, within $770-1050 \mathrm{~cm}^{-1}$ and $850-$ $1000 \mathrm{~cm}^{-1}$, is assigned to the presence of suboxides ${ }^{15,24}$ in the films obtained at these conditions. A week band also emerges at $\sim 900 \mathrm{~cm}^{-1}$ in the spectra of the films oxidized at $250{ }^{\circ} \mathrm{C}$.

As is known, ${ }^{1,2,6-8}$ the formation of ultrathin $\mathrm{SiO}_{2}$-based layer at the interface with $\mathrm{Si}$ is unavoidable during formation of a number of high- $\kappa$ dielectrics on $\mathrm{Si},\left(\mathrm{Ta}_{2} \mathrm{O}_{5}\right.$ is not an exception). We have no strong indication for the presence of $\mathrm{Si}-\mathrm{O}$ stretching band in the spectra (typically around $\left.1070-1100 \mathrm{~cm}^{-1}\right)$. Only the film obtained at $350{ }^{\circ} \mathrm{C}$, [Fig. 1(b)] exhibits very small bands in this region which can be attributed to the presence of $\mathrm{Si}-\mathrm{O}-\mathrm{Si}$ stretching vibration mode. ${ }^{25}$ These peaks do not change with varying $P$ and have negligible intensity which means that if there is an interfacial layer containing $\mathrm{SiO}_{2}$ and/or intermediate oxidation states of $\mathrm{Si}$, it is extremely thin.

\section{B. XRD results}

Figure 2 presents the XRD spectra of laser-oxidized Ta films grown at various substrate temperatures for two representative tantalum oxide thicknesses $(\sim 20$ and $40 \mathrm{~nm})$. All of the samples corresponding to certain $T_{s}$ and $d$ showed identical spectra. No diffraction peaks except for those from Si substrate (the intensive peak at $33.26^{\circ}$ ) were observed in the spectra of thinner films $(22 \mathrm{~nm})$ obtained at $T_{s}=300$ and $350{ }^{\circ} \mathrm{C}$ - the shape of the spectra indicates an amorphous structure of $\mathrm{Ta}_{2} \mathrm{O}_{5}$. The oxidation, however, at $400{ }^{\circ} \mathrm{C}$, 


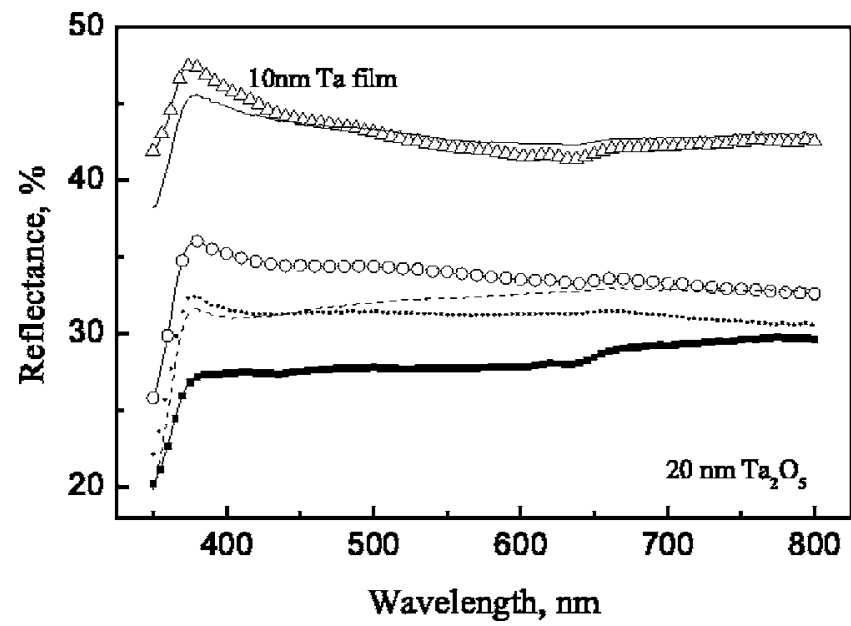

FIG. 3. Reflectance spectra of $20 \mathrm{~nm}$ laser-oxidized $\mathrm{Ta}_{2} \mathrm{O}_{5}$ at various substrate temperatures, $P=3.3 \mathrm{~J} / \mathrm{cm}^{2}:(一) T_{s}=250{ }^{\circ} \mathrm{C}$, (○-○-○) $T_{s}=300{ }^{\circ} \mathrm{C}$, $(\cdots) \quad T_{s}=350{ }^{\circ} \mathrm{C} ; \quad(\square \mathbf{\square}) T_{s}=400{ }^{\circ} \mathrm{C}: \quad P=3.2, \quad 3.3 \mathrm{~J} / \mathrm{cm}^{2} ; \quad---P$ $=3.2 \mathrm{~J} / \mathrm{cm}^{2}, T_{s}=350{ }^{\circ} \mathrm{C} ;(\triangle \triangle \triangle)$ reflectance spectrum of $10 \mathrm{~nm}$ Ta film on heated substrate, $T_{s}=250-400{ }^{\circ} \mathrm{C}$, (see the text).

induced the crystallization giving rise to specific diffraction lines typical of orthorhombic $\beta$ phase ${ }^{26}$ (x-ray diffraction file, Card No. 71-0639). The peaks (at $23.24^{\circ}$ and at $28.26^{\circ}$ ) with small intensity and relatively broad full width at half maximum (FWHM) of $0.635^{\circ}$ and $0.471^{\circ}$, respectively, indicate a low level of crystallization.

The spectra of thicker oxide layers $(\sim 40 \mathrm{~nm})$ show no indication of crystallization when $T_{s}$ is below $350{ }^{\circ} \mathrm{C}$ - only strong diffraction signal from the substrate is present. The spectrum of the layers oxidized at $350{ }^{\circ} \mathrm{C}\left(\right.$ or $400{ }^{\circ} \mathrm{C}$ ), Fig. 2(d), shows very small diffraction lines whose positions correspond to reflexes of orthorhombic $\beta$ phase. Concerning the crystal phase and the shape of XRD spectra, both substrate temperatures are identical. The substrate temperature leading to crystallization is therefore between 350 and $400{ }^{\circ} \mathrm{C}$ for thinner films (up to $20-25 \mathrm{~nm}$ ) and close to $350{ }^{\circ} \mathrm{C}$ for thicker films $(\sim 40 \mathrm{~nm})$. The polycrystalline $\mathrm{Ta}_{2} \mathrm{O}_{5}$ can be identified as the low temperature $\beta-\mathrm{Ta}_{2} \mathrm{O}_{5}$ phase, whereas, the peaks in the spectra of thicker films are not well pronounced which reflect the very weak extent of crystallization. Then, it can be concluded that at $T_{s}$ $<350{ }^{\circ} \mathrm{C}, \mathrm{Ta}_{2} \mathrm{O}_{5}$ obtained by laser oxidation is amorphous being independent of the film thickness (up to $\sim 40 \mathrm{~nm}$ ). At higher temperatures, the films crystallize- the thicker layers crystallize at lower $T_{s}$ as compared to the thinner one. Obviously, the higher substrate temperature stimulates the formation of crystal phase, but the effect is definitely weak and even weaker for greater oxide thicknesses.

In terms of XRD analysis, no evidence was found for tantalum silicide formation or segregation of metallic constituents, which could act as a leakage current enhancement factor.

\section{Reflectance spectra and refractive index}

Figure 3 shows the influence of the substrate temperature on the reflectance spectra of $20 \mathrm{~nm} \mathrm{Ta}{ }_{2} \mathrm{O}_{5}$ films oxidized at laser beam energy density of $3.3 \mathrm{~J} / \mathrm{cm}^{2}$. The small changes in $P$ have no effect on the reflectance of the layers obtained at $T_{s}=350$ and $400{ }^{\circ} \mathrm{C}$; the curves corresponding to $P=3.2$ and $3.3 \mathrm{~J} / \mathrm{cm}^{2}$ are almost the same. Reflectance spectrum for $10 \mathrm{~nm}$ Ta film on $\mathrm{Si}$, (i.e., a spectrum of the initial sample before laser oxidation) is also presented. As $T_{s}$ increases from 250 to $400{ }^{\circ} \mathrm{C}$, the reflectance $R$ decreases and the effect is more pronounced at smaller wavelengths, $\lambda$ : the decrease $\Delta R$ in $R$ is $17 \%-18 \%$ in the ultraviolet region $(\lambda=350-400 \mathrm{~nm})$, and $\Delta R=13 \%-17 \%$ in the visible one. The reflectance drop indicates an increase in the optical thickness, which is defined as the product of the refractive index, $n$, of the layer and its physical thickness, $d$. The reflectance, $R$, decreases with increasing $T_{s}$ and the curves are practically shifted parallel to each other with $\Delta R$ of $\sim 10 \%$. The highest drop of $R$, in the whole spectral range, is detected when $T_{s}$ changes from 250 to $300{ }^{\circ} \mathrm{C}$, implying that the active oxidation starts somewhere at the substrate temperature between 250 and $300{ }^{\circ} \mathrm{C}$. Additional evidence for this suggestion is seen from the reflectance spectrum of a Ta film on $\mathrm{Si}$ after heating the substrate without laser oxidation, (Fig. 3). The spectrum of metallic Ta does not change with varying $T_{s}$ from 250 to $400{ }^{\circ} \mathrm{C}$ indicating that there is no any thermal oxidation without laser action. The spectrum of Ta film and the laser-oxidized layer at $250{ }^{\circ} \mathrm{C}$ are also the same, i.e., even though there are small optical thickness variations, the reflectance is not sensitive to them. The laseroxidized films exhibit, however, considerably different behavior than metallic Ta, when the oxidation takes place at $T_{s}$ higher than $250^{\circ} \mathrm{C}$. So, we can conclude that the active oxidation process starts, i.e., the transition from metallic Ta to tantalum oxide, at $T_{s}$ greater than $250{ }^{\circ} \mathrm{C}$. Furthermore $\left(T_{s} \geqslant 300{ }^{\circ} \mathrm{C}\right)$, an increase of $T_{s}$ with a step of $50{ }^{\circ} \mathrm{C}$ resulted in a constant but smaller reduction of $R,(\Delta R \sim 4 \%$ as compared to $\Delta R$ when $T_{s}$ changes from 250 to $300{ }^{\circ} \mathrm{C}$ ). In fact, the reflectance behavior is related with changes of optical thickness, $n d$, of the layer. Since $R$ is a periodical function of $n d$ with a periodicity of $\lambda / 2$, it changes with variation of $n d$ from zero to $\lambda / 4$, and depends on the ratio between refractive index $n$ of the layer and of the substrate, $n_{\text {sub }}$, respectively, ( $R$ decreases when $n / n_{\text {sub }}<1$ and vice versa). If we suppose that the values of $n$ are close to 2-2.2, which are the typical values of stoichiometric $\mathrm{Ta}_{2} \mathrm{O}_{5},{ }^{7,16,25}$ the optical thickness will vary from $\lambda / 8$ to $\lambda / 18$ in the whole spectral range and it will be generally smaller than $\lambda / 4$. Considering that $n / n_{\text {sub }}<1,\left(n_{\text {sub }}=5.60-3.66\right.$ in the used spectral range for $\mathrm{Si}$ wafer), the decay of $R$ could be attributed to the increase of optical thickness. As far as the films' thickness is constant $(20 \mathrm{~nm})$ independently of $T_{s}$ an increase of $n$ is the only possible explanation of the greater values of $n d$ at higher $T_{s}$. It should be noted, however, that it is hard to draw a conclusion considering only the $R$ spectral behavior because of the sophisticated relationship between $R$ and $n$. The key role of the refractive index in these characteristics of the optical thickness is fairly plausible. The values of $n$, obtained after experimental reflectance spectra fitting, with respect to $\lambda$ between 400 and $800 \mathrm{~nm}$ for three substrate 


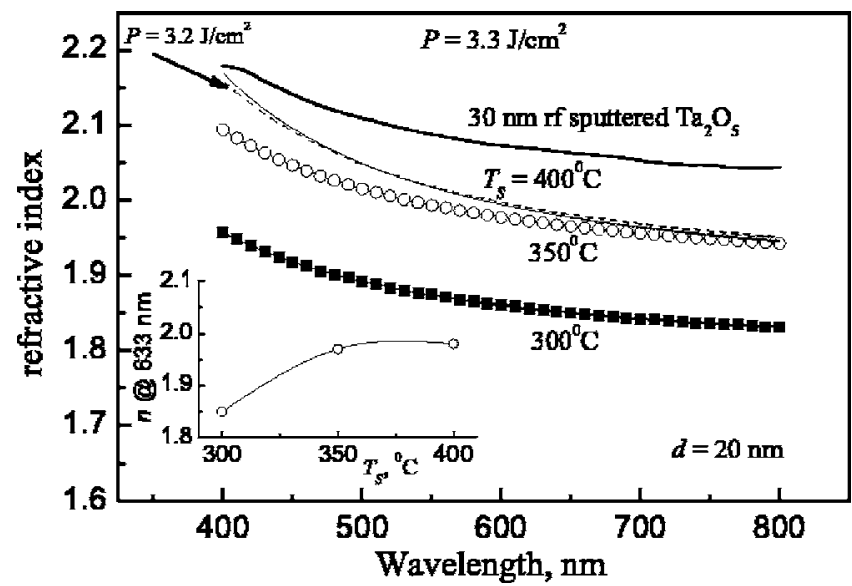

FIG. 4. Refractive index as a function of $\lambda$ for laser-oxidized films obtained at different conditions; $n(\lambda)$ dependence of rf-sputtered $\mathrm{Ta}_{2} \mathrm{O}_{5}$ (taken from Ref. 27) is shown for comparison. The inset shows variation of $n$ at $633 \mathrm{~nm}$ with $T_{s}$.

temperatures are presented in Fig. 4. The data for two values of $P,\left(T_{s}=400{ }^{\circ} \mathrm{C}\right)$ are also shown as well as a curve of rf-sputtered $\mathrm{Ta}_{2} \mathrm{O}_{5}(30 \mathrm{~nm}),{ }^{27}$ for comparison. All spectra with exception of the case $T_{s}=250{ }^{\circ} \mathrm{C}$ are fitted very well using the model of single oxide layer. This confirms the assumption that the active laser oxidation obviously occurs at $T_{s}>250{ }^{\circ} \mathrm{C}$. The ellipsometrical values of $n$ are 1.9-2 for the $10 \mathrm{~nm}$ Ta oxidized films and $1.95-2.1$ for $20 \mathrm{~nm}$ ones and these are in a very good accordance with the calculated values at $\lambda \approx 633 \mathrm{~nm}$. Generally, the dispersion curves exhibit a typical wavelength dependence of $n$ for non- or slightly absorbing film, i.e., $n$ decreases with increasing $\lambda$ and tend to saturate at higher $\lambda(\lambda \geqslant 600 \mathrm{~nm}) . n$ increases with $T_{s}$ and the effect is more pronounced when $T_{s}$ varies from 300 to $350{ }^{\circ} \mathrm{C}$, i.e., the film undergoes a structural transformation upon oxidizing at $T_{s}$ between 300 and $350{ }^{\circ} \mathrm{C}$, while the refractive index is improved slightly for the highest $T_{s}$. The degree of the improvement depends on $\lambda$ : the effect is stronger for the shorter wavelength region, $(\sim 400-600 \mathrm{~nm})$; the maximum increase of $n$, from 2.09 to 2.17 is detected at $\lambda=400 \mathrm{~nm}$. The impact of $T_{s}$ on refractive index suggests that the growth processes have different controlling mechanisms at various substrate temperatures resulting in the layers with varying density, (i.e., different $n$ ). The dependence of $n$ on $T_{s}$ at a photon energy of $1.96 \mathrm{eV}$, $(\lambda=633 \mathrm{~nm})$, presented as the inset of Fig. 4, confirms that the influence of $T_{s}$ is essential in the range $300-350{ }^{\circ} \mathrm{C}$, where $n$ arises with 0.12 , achieving the value of 1.98 , similar to values reported for as-fabricated $\mathrm{Ta}_{2} \mathrm{O}_{5}$ films obtained by other methods. ${ }^{6,7,16,27}$ Further, the highest $T_{s}$ does not lead to any increase of refractive index at $633 \mathrm{~nm}$. Obviously, the dense enough as-grown oxides can be achieved at $T_{s}=350-400{ }^{\circ} \mathrm{C}$. As is seen from Fig. 4 , the small variations of laser energy density (at identical $T_{s}$ ) do not influence on refractive index. It is worth noting that the refractive indices of laser-oxidized films, even for the highest $T_{s}$, do not reach those corresponding to rf-sputtered films with similar thicknesses, indicating that the laser oxidation provides lower re-

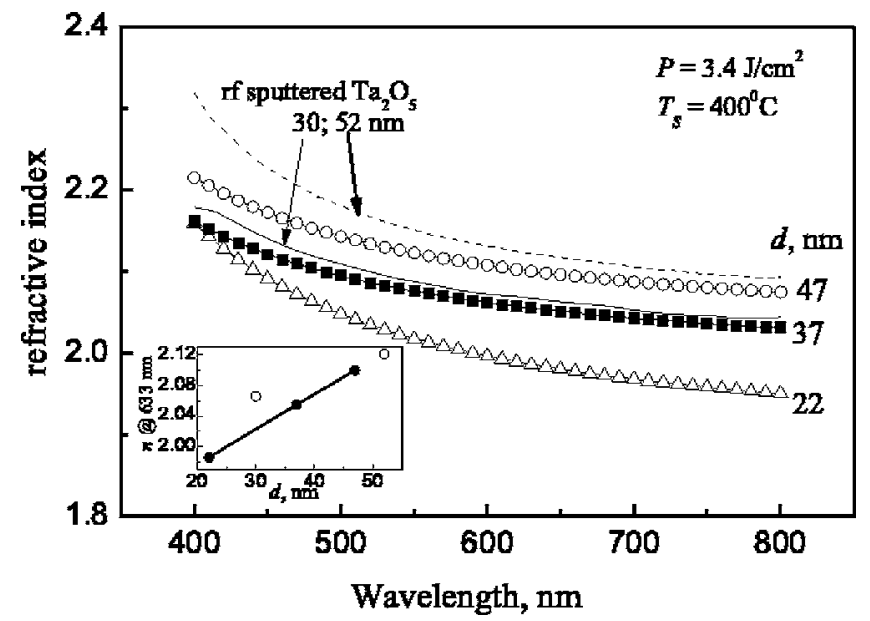

FIG. 5. Dependence of refractive index on $\lambda$ for the laser-oxidized films with various physical thickness. The curves corresponding to two rf-sputtered $\mathrm{Ta}_{2} \mathrm{O}_{5}$ samples (taken from Ref. 27) are given for comparison. The inset shows the variation of $n$ vs $d$; laser oxidized; $\bigcirc$ sputtered $\mathrm{Ta}_{2} \mathrm{O}_{5}$.

fractive index as compared to the deposition process by $\mathrm{rf}$ sputtering of Ta target in $\mathrm{Ar}+\mathrm{O}_{2}$ mixture. ${ }^{6,27}$ The poor density, high porosity, and oxygen deficiency of the layers are the possible reasons for the lower $n$ values. However, both types of $\mathrm{Ta}_{2} \mathrm{O}_{5}$ obey stronger dispersion in the shorter wavelength region, $\approx 400-650 \mathrm{~nm}$. This could be attributed to the presence of suboxides which causes the absorption edge to shift to larger wavelengths or to the large surface roughness. The suggestion of suboxides is a simpler explanation and it is completely consistent with the data of Auger and x-ray photoelectron spectroscopy (XPS) analyses of rf-sputtered samples ${ }^{7}$ where the presence of Ta suboxides was demonstrated through the depth of the layers. On the other hand, FTIR analysis indicates relatively weak presence of suboxides in laser-grown $\mathrm{Ta}_{2} \mathrm{O}_{5}$. In order to clarify this point, the detailed XPS measurements, including depth profiles, are now in progress for the laser-oxidized samples.

The index of refraction increases as the film thickness increases. The dispersion curves of $n$ for three oxide thicknesses as measured ellipsometrically, (under otherwise the identical conditions, $P=3.4 \mathrm{~J} / \mathrm{cm}^{2}, T_{s}=400{ }^{\circ} \mathrm{C}$, corresponding to more efficient oxidation process) are presented in Fig. 5. The data of as-deposited rf-sputtered 30 and $52 \mathrm{~nm}-$ thick $\mathrm{Ta}_{2} \mathrm{O}_{5}$ films ${ }^{27}$ are also given for comparison. The highest refractive index is obtained for the thickest laser-oxidized layer $(47 \mathrm{~nm})$ : the values of $n$ are very close to those of $52 \mathrm{~nm}$ rf-sputtered $\mathrm{Ta}_{2} \mathrm{O}_{5}$, for $\lambda \geqslant 550 \mathrm{~nm}$ (the difference is only $0.01-0.03$ ), despite the laser-oxidized film being a little thinner. The values of $n$ in the whole spectral range for both $37 \mathrm{~nm}$ laser-oxidized $\mathrm{Ta}_{2} \mathrm{O}_{5}$ and $30 \mathrm{~nm}$ sputtered one are almost the same. Therefore, the results suggest that the laser oxidation of Ta films to thicknesses of $\mathrm{Ta}_{2} \mathrm{O}_{5}$ above $\sim 35 \mathrm{~nm}$ provides layers with the same density, (in terms of refractive index) as rf-sputtered $\mathrm{Ta}_{2} \mathrm{O}_{5}$. Consequently, it can be expected that the similar chemical composition of the two types of oxides. The inset of the figure indicates the corresponding changes of refractive index at $633 \mathrm{~nm}$ with film thickness for 
laser-oxidized and rf-sputtered $\mathrm{Ta}_{2} \mathrm{O}_{5}$. Generally, the thickness dependence of $n$ seems to be attributed to the better density of thicker films, (densified oxides with a better stoichiometry), resulting in a reduction of interatomic spacing. Since $n$ is proportional to the electronic polarizability which is inversely proportional to the interatomic spacing, the reduction of this spacing for thicker films directly results in an increase of their refractive indices. The observed weaker dispersion of the thicker films as compared to the thinnest one suggests the improved stoichiometry of thick films too.

\section{CONCLUSION}

We have successfully demonstrated Nd:YAG laserassisted growth of $\mathrm{Ta}_{2} \mathrm{O}_{5}$ films $(20-50 \mathrm{~nm})$ by oxidation of deposited Ta film on Si by employing FTIR, XRD, and reflectance spectra analyses. The laser oxidation provides films whose structure, amorphous status, optical thickness, and refractive index can be effectively controlled by the substrate temperature $\left(250-400{ }^{\circ} \mathrm{C}\right)$. The active oxidation starts between 250 and $300{ }^{\circ} \mathrm{C}$ of substrate temperature and further the increase of substrate temperature leads to progressive improvement of film's density. The XRD data showed that the films grown at or below $350{ }^{\circ} \mathrm{C}$ are amorphous and the films grown at higher temperature are polycrystalline with orthorhombic structure. In fact, the substrate temperature leading to crystallization depends on the thickness of the layers; for the thinner layers (which are of practical interest) it is higher being between 350 and $400{ }^{\circ} \mathrm{C}$. The goal result here, however, is that in all cases the crystallization effect is definitely weak which can be very important for high- $\kappa$ application of laser-grown $\mathrm{Ta}_{2} \mathrm{O}_{5}$. Therefore, we can conclude that the most desirable growth condition with respect to amorphous status of the films, their stoichiometry and refractive index (i.e., dense films) is at substrate temperature close to the temperature (but without crossing it) when the crystallization starts. We also have indication that the lower- $\kappa$ interfacial layer at $\mathrm{Si}$ is extremely thin which means that this oxidation technique has the potential as an enabling technology for nanoscale high- $\kappa$ dielectric-based devices. The interfacial perfection will help to reduce the oxide equivalent thickness.

The refractive index increases with increasing the film thickness accompanied by a decrease of the dispersion implying a higher level of film densification and improved stoichiometry for thicker films. The thickest layers used here (45-50 nm) have refraction indices close to the typical values of bulk stoichiometric $\mathrm{Ta}_{2} \mathrm{O}_{5}$. All quantitative suboxide aspects of the layers, however, require a precise XPS analy- sis including depth profiling. Work is proceeding on this and we hope to report further on this topic in the near future.

\section{ACKNOWLEDGMENTS}

This work has been partly supported by Bulgarian National Science Foundation (Project No. F1508) and by TUBITAK (Scientific and Technical Council of Turkey) under Project No. TBAG/U68.

${ }^{1}$ International Technology Roadmap for Semiconductors (ITRS) (Semiconductor Industry Association, San Jose, 2003); http://public.itrs.net

${ }^{2}$ A. I. Kingon, J. P. Maria, and S. K. Streiffer, Nature (London) 406, 1032 (2000).

${ }^{3}$ S. Kamiyama, P. Lesaicherre, H. Suzuki, A. Sakai, I. Nishiyama, and A. Iskitani, J. Electrochem. Soc. 140, 1617 (1993).

${ }^{4}$ S. R. Jeon, S. W. Han, and J. W. Park, J. Appl. Phys. 77, 5978 (1995).

${ }^{5}$ J. V. Chrahn, P. E. Hellberg, and E. Olson, J. Appl. Phys. 84, 1632 (1998).

${ }^{6}$ E. Atanassova, Microelectron. Reliab. 39, 1185 (1999).

${ }^{7}$ E. Atanassova and T. Dimitrova, in Handbook of Surfaces and Interfaces of Materials, edited by H. S. Nalwa (Academic, San Diego, CA, 2001), Vol. 4, p. 439

${ }^{8}$ C. Chaneliere, J. L. Autran, R. A. B. Devine, and B. Balland, Mater. Sci. Eng., R. 22, 269 (1998).

${ }^{9}$ K. Kukli, J. Aarik, A. Aidla, O. Kohan, T. Uustare, and V. Sammelselg, Thin Solid Films 260, 135 (1995).

${ }^{10}$ Z. Mingfei, F. Zhengwen, Y. Haijun, Z. Zhuangjian, and Q. Qizong, Appl. Surf. Sci. 108, 399 (1997).

${ }^{11}$ Y. Nishimura, A. Shinkawa, H. Ujita, M. Tsuji, and M. Nakamura, Appl. Surf. Sci. 136, 22 (1998).

${ }^{12}$ J. Y. Zhang and I. W. Boyd, Appl. Surf. Sci. 168, 234 (2000).

${ }^{13}$ S. Boughaba, G. I. Sproule, J. P. McCaffrey, M. Islam, and M. J. Graham, Thin Solid Films 358, 104 (2000).

${ }^{14}$ J. Y. Kim, M. C. Nielsen, E. J. Rymaszewski, and T. M. Lu, J. Appl. Phys. 87, 1448 (2000).

${ }^{15}$ I. W. Boyd and J. Y. Zhang, Microelectron. Reliab. 40, 649 (2000).

${ }^{16}$ G. D. Wilk, R. M. Wallace, and J. M. Anthony, J. Appl. Phys. 89, 5243 (2001), and references therein.

${ }^{17}$ J. Y. Zhang, V. Dusastre, and I. W. Boyd, Mater. Sci. Semicond. Process. 4, 313 (2001).

${ }^{18}$ E. Atanassova, N. Novkovski, A. Paskaleva, and M. PesovskaGjorgjevich, Solid-State Electron. 46, 1887 (2002).

${ }^{19}$ M. Passacantando, F. Jolly, L. Lozzi, V. Salerni, P. Picozzi, S. Santucci, C. Corsi, and D. Zintu, J. Non-Cryst. Solids 322, 225 (2003).

${ }^{20}$ G. Aygun, E. Atanassova, A. Alicakir, L. Ozyuzer, and R. Turan, J. Phys. D 37, 1569 (2004).

${ }^{21}$ G. Aygun, E. Atanassova, R. Turan, and Tz. Babeva, Mater. Chem. Phys. 89, 316 (2005)

${ }^{22}$ Tz. Babeva, S. Kitova, B. Mednikarov, and I. Konstantinov, Appl. Opt. 41, 3840 (2002).

${ }^{23}$ T. F. Coleman and Y. Li, SIAM J. Optim. 6, 418 (1996).

${ }^{24}$ J. Y. Zhang, Q. Fang, and I. W. Boyd, Appl. Surf. Sci. 138-139, 320 (1999).

${ }^{25}$ J. J. Yu, J. Y. Zhang, and I. W. Boyd, Appl. Surf. Sci. 186, 57 (2002).

${ }^{26} \mathrm{X}$-ray diffraction file, ICDD.

${ }^{27}$ Tz. Babeva, E. Atanassova, and J. Koprinarova, Phys. Status Solidi A 202, 330 (2005). 